\title{
Rozwój onkologii na Podkarpaciu: część II — do 1999 roku
}

\author{
Jan Gawełko
}

Kolejne lata działalności Wojewódzkiego Szpitala Onkologicznego w Rzeszowie wykazały, jak wielkie jest na Podkarpaciu zapotrzebowanie w zakresie lecznictwa onkologicznego. W 1985 r. dr Józef Małek zgłosił kompleksowy plan budowy nowego Szpitala Onkologicznego w Rzeszowie. Wniosek ten, pozytywnie zaopiniowany przez prof. Skołyszewskiego, został w 1986 r. przyjęty do realizacji. W kwietniu 1988 projekt zakładający budowę szpitala onkologicznego, planowanego na 300 łóżek, w tym 50 dla stanów lekkich, oraz zespołu sal operacyjnych został pozytywnie zaopiniowany przez ministra zdrowia. Koncepcja ta nie została jednak zrealizowana, i w 1990 r. podjęto decyzję o rozwiązaniu Wojewódzkiego Szpitala Onkologicznego w Rzeszowie oraz włączeniu jego Oddziałów do Szpitala Wojewódzkiego Nr 1.W lutym 1992 r. rozpoczęto leczenie telegammaterapią w nowym pawilonie bomby kobaltowej, a wkrótce potem curieterapię zastąpiono brachyterapią after-loading LDR, MDR. W latach 1992-1997 działające na bazie Oddziałów onkologicznych Stowarzyszenia zorganizowały szereg konferencji krajowych i międzynarodowych o tematyce onkologicznej. W 1995 r. utworzono na bazie oddziałów i zakładów onkologicznych Rzeszowski Ośrodek Onkologiczny. W ramach jego rozbudowy uzyskano kolejną bombę kobaltową oraz dwa dwustanowiskowe aparaty Selectron LDR/MDR. W listopadzie 1999 r. Rzeszowski Ośrodek Onkologiczny przekształcono w działające do dziś w strukturach Wojewódzkiego Szpitala Specjalistycznego Podkarpackie Centrum Onkologii.

\section{The early years of oncology in the Podkarpacie Region}

The activities of the Provincial Oncological Hospital in Rzeszów show how great is the demand for oncology treatment in the Lower Carpathians province. In 1985, Dr. Józef Małek submitted a comprehensive construction plan for a new Oncological Hospital in Rzeszów. This proposal received approval from Prof. Skołyszewski and was approved for implementation in 1986. In April 1988, the project for the construction of the Oncological Hospital with 300 beds, patients and the operating rooms, was given a positive opinion by the Minister of Health. However, this was not implemented and in 1990, it was decided to dissolve the Provincial Oncological Hospital in Rzeszów and join it to the wards of Provincial Hospital No. 1. In February 1992, treatment using telegamma therapy was started in the new cobalt bomb pavilion, and soon telecurie-therapy was replaced by LDR and MDR brachytherapy. In the years 1992-1997, an association acting on the basis of oncology Branches organised a series of national and international conferences on oncology. In 1995, on the basis of oncology Branches and Institutions, the Oncology Centre was established in Rzeszów. As part of its expansion, another cobalt bomb and two workstations for LDR/MDR Selectron were acquired. In November 1999, the Oncology Center in Rzeszów was operating as it does today, and is the Specialist District Hospital — Lower Carpathians Oncology Center.

NOWOTWORY Journal of Oncology 2015; 65, 2: 151-156

Słowa kluczowe: Podkarpackie Centrum Onkologii, onkologia w Rzeszowie, ośrodki onkologiczne w Polsce Key words: oncology, history, Lower Carpathians Oncology Centre 
Wojewódzki Szpital Onkologiczny w Rzeszowie był w latach 80. jedyną jednostką onkologiczną stosującą radio- i curieterapię. Pomimo posiadania 3 aparatów do rentgenoterapii oraz zestawu źródeł radowych umożliwiających konfigurowanie ładunków stosownie do potrzeb klinicznych — potrzeby zarówno w zakresie bazy lokalowej, jak i sprzętowej w regionie nadal przerastały możliwości Szpitala. Należało stworzyć odpowiednie warunki zarówno pod względem bazy łóżkowej, jak i aparaturowej. Już w 1975 roku sygnalizowano konieczność instalacji, podobnie jak w innych ośrodkach regionalnych, bomby kobaltowej [1].

Sprawy zarówno bazy, jak i infrastruktury były przedmiotem starań ówczesnego dyrektora dr. Józefa Małka, który we wrześniu 1985 roku po raz kolejny wystąpił do władz wojewódzkich z inicjatywą budowy pawilonu onkologii z lokalizacją w planowanym zespole Szpitala Wojewódzkiego nr 2 przy ul. Lwowskiej. Wniosek został przyjęty, a o zaopiniowanie poproszono dyrektora Instytutu Onkologii w Krakowie prof. dr. hab. Jana Skołyszewskiego. W wyniku jego pozytywnej opinii Wydział Zdrowia Wojewódzkiej Rady Narodowej w Rzeszowie skierował w styczniu 1986 roku do Zarządu Inwestycji Służby Zdrowia i Opieki Społecznej wniosek w sprawie budowy szpitala onkologicznego — do realizacji. W maju tegoż roku Biuro Studiów i Projektów Służby Zdrowia w Warszawie przyjęło zadanie, i w sierpniu 1986 roku przedstawiono pierwszą wersję programu użytkowego Szpitala Onkologicznego w Rzeszowie.

W listopadzie 1986 roku, podczas narady w Zarządzie Inwestycji Służby Zdrowia i Opieki Społecznej, ustalono, że będzie to inwestycja o nazwie Wojewódzki Szpital Onkologiczny, docelowo na 300 łóżek, w tym 250 szpitalnych i 50 - dla stanów lekkich oraz o trzech salach operacyjnych [2].

W dniu 25 kwietnia 1988 roku Zarząd Inwestycji Służby Zdrowia w Rzeszowie przekazał dyrektorowi Wojewódzkiego Szpitala Onkologicznego decyzję Ministra Zdrowia z 15 kwietnia tegoż roku: „Program Wojewódzkiego Szpitala Onkologicznego w Rzeszowie opiniuję pozytywnie" [3, 4]. W lipcu 1989 roku Zarząd Inwestycji przekazał dyrektorowi Wojewódzkiego Szpitala Onkologicznego w Rzeszowie koncepcję architektoniczno-przestrzenną oraz szacunkowe zestawienie kosztów. Dalszego biegu koncepcji rozwoju onkologii już nie nadano.

W grudniu 1990 roku zapadła decyzja wojewody rzeszowskiego o likwidacji Wojewódzkiego Szpitala Onkologicznego jako samodzielnej jednostki i włączeniu jego struktur do Wojewódzkiego Szpitala Zespolonego Nr 1 [5]. Reorganizacja zastała rzeszowską onkologię w trudnym momencie. Wielokrotnie postulowana budowa bunkra dla bomby kobaltowej, rozpoczęta w 1988 roku, była na dzień reorganizacji ukończona, jednak dostarczone źródło kobaltowe nie nadawało się do eksploatacji.

Jak wykazało dochodzenie, z powodu niewłaściwego składowania całej partii źródeł do aparatów Alcyon II

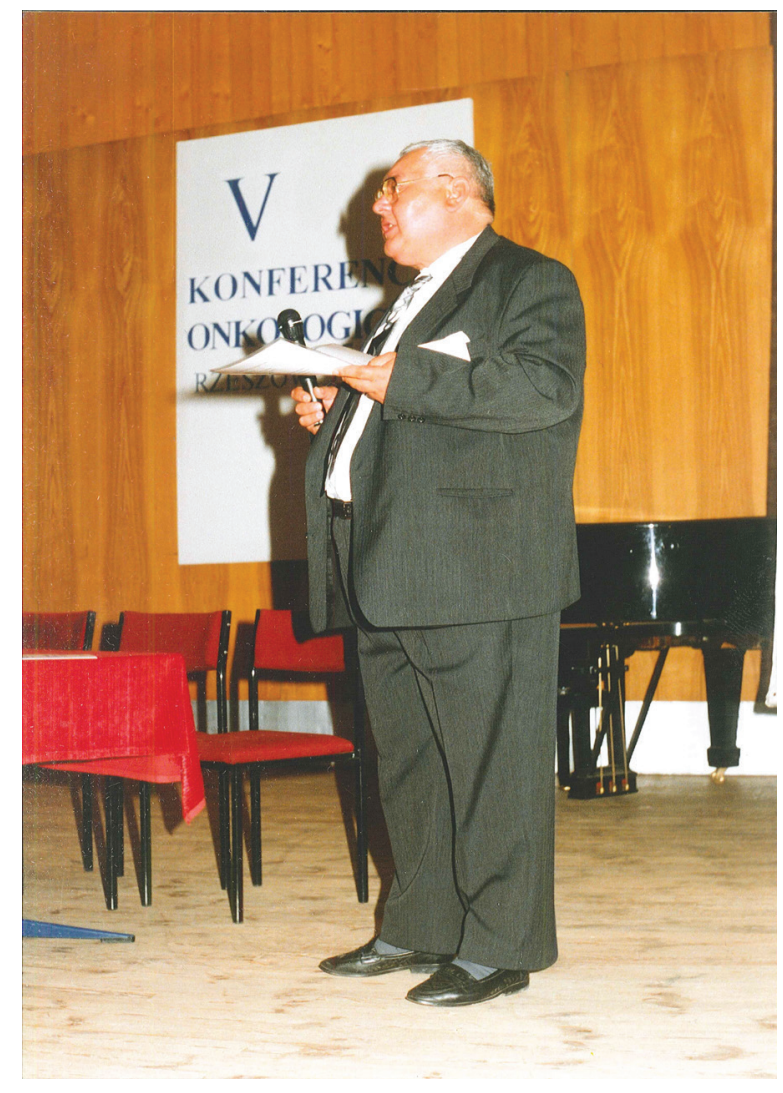

Rycina 1. Dr med. Wiesław Fabisiak

— przed dostarczeniem ich do ośrodków onkologicznych, w tym również do Rzeszowa i Brzozowa - doszło do trwałego zablokowania mechanizmów wysuwania źródła. Postępowanie w sprawie ustalenia przyczyn oraz zakupu nowego źródła było długotrwałe. W wyniku zabiegów wielu ludzi dobrej woli wojewoda rzeszowski zakupił ostatecznie źródło ze środków Urzędu Wojewódzkiego.

W tej trudnej sytuacji ogromnej pomocy w rozpoczęciu stosowania telegammaterapii udzielił Instytut Onkologii w Krakowie, Oddział Centrum Onkologii — Instytutu im. Marii Skłodowskiej-Curie. W dniu 1 lutego 1992 roku w obecności jego dyrektora prof. dr. hab. Jana Skołyszewskiego wykonano pierwsze seanse telegammaterapii [6].

Podobnej pomocy udzieliły Instytuty Onkologii w Krakowie i Gliwicach, gdy w wyniku starań dr. n. med. Wiesława Fabisiaka — ordynatora Oddziału Ginekologii Onkologicznej - uzyskano 2 aparaty typu UR-1 produkcji Polon Poznań, wyposażone w 24 źródła Cs 137 o aktywności 29,7 GBq oraz zezwolenie CLOR na ich eksploatację. Dzięki pomocy tych Instytutów zorganizowano i rozbudowano pracownię brachyterapii LDR/MDR, umożliwiając leczenie w systemie dwustanowiskowym [7].W działaniach tych znaczący udział miały mgr Emilia Samojedny, kierownik rzeszowskiego Zakładu Fizyki Medycznej oraz kierownik zespołu techników pani Ludwika Czyż [8]. 
Ponieważ włączenie w struktury Szpitala Wojewódzkiego Oddziałów, Pracowni i Zakładów o profilu onkologicznym nie przewidywało kontynuowania jakiejkolwiek działalności o charakterze ośrodka regionalnego, grupa onkologów i pracowników naukowych Instytutu Medycyny Klinicznej powołała w 1990 roku Stowarzyszenie Wspierania Ośrodka Onkologicznego w Rzeszowie, które stało się animatorem szkoleń, konferencji oraz szeregu działań mających na celu umożliwienie lekarzom odbywania staży, udziału w kursach i zjazdach oraz zapewnienie dostępu do literatury fachowej. Przewodniczącą Rady Stowarzyszenia została prof. dr hab. med. Władysława Garska, a członkami — m.in. prof. dr hab. Andrzej Bętkowski i dr n. farm. Wiesław Rytarowski [9]. Pojawiło się też kolejne źródło wsparcia. W 1991 roku, z inicjatywy dr. Wiesława Fabisiaka, powstał w Rzeszowie oddział stowarzyszenia „,Medecins du Monde", któremu od lutego 1992 roku udzieliła locum Okręgowa Izba Lekarska w Rzeszowie. Dzięki współpracy z centralą „Medecins du Monde"w Paryżu oraz konsulatem generalnym Francji w Krakowie udało się uzyskać pomoc w organizacji szkoleń i konferencji, a także zorganizować przeszło 40 transportów leków i materiałów sanitarnych do Rzeszowa [10]. W uzgodnieniu z władzami wojewódzkimi, po dokonaniu niezbędnych odpraw i formalności, leki te były sortowane w aptece szpitala pod nadzorem mgr Danuty Rudnickiej.

Preparaty kwalifikujące się do użytku szpitalnego, a zwłaszcza onkologicznego, były przyjmowane do apteki szpitala, natomiast preparaty dla lecznictwa otwartego były przekazywane do bezpłatnego wydawania na recepty wszystkim potrzebującym. Wkrótce zaistniała potrzeba utworzenia stałego punktu wydawania leków, gdyżzarówno popyt, jak i podaż gwałtownie rosły.

Zarówno apteka, jak i ośrodek onkologiczny były wizytowane przez konsula generalnego Republiki Francuskiej w Krakowie pana Didiera Destremau, przedstawiciela ambasady w Warszawie pana Eryka Foltzer, przedstawicieli kierownictwa,,Medecins du Monde" oraz dr. C. Chassaigne'a i dr. J-P. Dilhuydy z „Fundacji Bergonie" w Bordeaux.

Od 1992 roku rozpoczęto regularną organizację corocznych konferencji onkologicznych, które z udziałem kadry Instytutów Onkologii w Krakowie i Warszawie przybliżały nie tylko onkologom, ale całemu środowisku postępy w tej dziedzinie nauk medycznych. Działania te organizowane były przez Stowarzyszenie Wspierania Ośrodka Onkologicznego oraz przez,"Medecins du Monde", zwłaszcza w aspekcie kontaktów zagranicznych. Do 1999 roku zorganizowano 7 konferencji z udziałem tak znanych postaci jak profesorowie: Jan Skołyszewski, Marian Reinfuss, Krzysztof Urbański, Jerzy Mituś, Bogdan Glinski, Stanisław Korzeniowski, Michał Waligórski, Andrzej Hliniak, Andrzej Kułakowski, Marek P. Nowacki, Zbigniew Wronkowski, Aleksander Niezabitowski, Jan Zieliński, Zofia Dańczak-Ginalska, Przemysław Janik, Zbigniew Chłap, Krzysztof Bujko, Maciej Krzakowski, Edward Towpik, Anna Gasińska, dr med. Janusz Meder i wielu innych.
W konferencjach uczestniczyli też goście z zagranicy: prof. Agnes Guitry z Houston, dr Tammy Polit z Uniwersytetu Indiana, prof. Arwed Junker z Kliniki Onkologii w Minden, dr J.P Dilhuydy z Centrum Onkologii w Bordeaux, prof. J. P. Le Bourgeois z Paryża. Ostatnia z konferencji, która odbyła się w październiku 1997 r. w Solinie-Jaworze, była jednocześnie XI Konferencją Naukowo-Szkoleniową Sekcji Radioterapii PTO. Konferencje umożliwiły również przybliżenie spraw rzeszowskiej onkologii zapraszanym gościom i wykładowcom. W efekcie powstała możliwość odbycia stażu w MD Anderson Cancer Center w Houston dla dr. Jerzego Mazurka w zakresie diagnostyki nowotworów piersi, dla dr. Jana Gawełki w Leuven z zakresu radioterapii oraz dla dr. Stanisława Samołyka w Minden.

Kontynuowano również starania o doposażenie Zakładów i Pracowni onkologicznych. Z perspektywy czasu nie można tym działaniom odmówić skuteczności. Zaowocowały one uzyskaniem w tym samym roku aparatu do powierzchniowej rentgenoterapii konwencjonalnej Stabilipan, w rok później nowoczesnego mammografu Philips, w 1995 roku dwustanowiskowego Selectronu LDR, wyposażonego w 36 źródeł Cs 137, a w 1996 roku — symulatora Siemens [11-14]. W oparciu o posiadaną aparaturę i kadrę usamodzielniono pracownie mammografii i USG, których kierownictwo objął po powrocie z Houston dr Jerzy Mazurek.

W 1995 roku działalność onkologii została ostatecznie ujęta w ramy organizacyjne. Podczas V Konferencji Onkologicznej wojewoda rzeszowski dr Kazimierz Surowiec ogłosił utworzenie w ramach Wojewódzkiego Szpitala Zespolonego Nr I Rzeszowskiego Ośrodka Onkologicznego [15].

Wkrótce potem, w czerwcu 1996 roku, do rzeszowskiego Ośrodka przybyła znana z działalności charytatywnej Lady Ryder of Warsaw, której fundacja poszukiwała lokalizacji dla stworzenia piętnastego już w Polsce obiektu — tym razem o profilu onkologicznym. Lady Ryder zwiedziła Oddziały i Zakłady rzeszowskiej onkologii oraz spotkała się z władzami województwa, a następnie zwiedziła proponowany przez lekarza wojewódzkiego dr. med. Aleksandra Panka teren - sanatorium Górno, gdzie zaakceptowała lokalizację Domu Sue Ryder. W Dyrekcji PCO eksponowany jest jej serdeczny list, przesłany na ręce dr. Gawełki po powrocie do Anglii. Wybudowany po jej wizycie pawilon, tak jak inne Domy Sue Ryder służy potrzebującym pod nazwą SPZOZ „Sanatorium” w Górnie.

With warmest wishes.

$$
\text { Ryden of havian }
$$

Rycina 2. Autograf Sue Ryder w liście do dr. Jana Gawełki 
W kolejnych latach podejmowano dalsze starania o rozbudowę onkologii — budowę bunkrów oraz wyposażenie ośrodka w przyspieszacze liniowe. Działania te wspierał Instytut Onkologii w Krakowie, w szczególności w osobach prof. Jana Skołyszewskiego jako konsultanta regionalnego oraz prof. Mariana Reinfussa [16]. W wyniku tych działań uzyskano w 1998 roku nową bombę kobaltową Theratron 780 E oraz system planowania leczenia Theraplan, drugi aparat dwustanowiskowy do brachyterapii typu Selectron, kolejny mammograf Elscint-Glory z wyposażeniem do biopsji cienkoigłowej oraz szereg kompletów aparatury fizycznej, jak analizatory pola, fantomy, dozymetry i dawkomierze [17-19]. Po otrzymaniu drugiego Selectronu Zakład Brachyterapii dysponował możliwością jednoczesnego stosowania brachyterapii u 4 chorych. W związku z tym przekazano I Katedrze i Klinice Ginekologii Akademii Medycznej we Wrocławiu 2 posiadane aparaty UR-1 wraz z kompletem źródeł cezowych i dokumentacją [20].

W grudniu 1998 roku, po 28 latach, ostatecznie zamknięto w Rzeszowie rozdział leczenia radem, jakkolwiek od 1990 roku używany był on tylko sporadycznie do wyjątkowo nietypowych lokalizacji. Przekazanie 33 źródeł do Zakładu Doświadczalnego Unieszkodliwiania Odpadów Promieniotwórczych Instytutu Energii Atomowej w Świerku po raz ostatni zgromadziło pracowników, którzy dokonywali aplikacji radowych, byli to: dr Józef Płaza, dr Wiesław Fabisiak, dr Jan Gawełko, mgr Kazimierz Puc, piel. oddziałowa Małgorzata Materna, piel. Helena Ożóg i piel. Janina Pacanowska [20, 21]. Dekadę 1990-1999 rzeszowska onkologia kończyła ze świadomością zasadniczego postępu kadrowo-aparaturowego, organizacji szeregu znaczących konferencji naukowych oraz dobrze wypełnionego wobec społeczeństwa regionu obowiązku.

Do końca 1999 roku wykonano 148828 seansów telegammaterapii oraz stosowano brachyterapię LDR/MDR u ponad 1500 chorych. Wykonano ponad 22450 mammografii. W samym tylko 1997 roku hospitalizowano ponad 4000 chorych i przyjęto ich ponad 25000 w Wojewódzkiej Poradni Onkologicznej. Kadra lekarska liczyła 31 osób wszystkich specjalności onkologicznych [23]. Uzyskano od Klinik Instytutu Onkologii w Krakowie upoważnienie do stosowania techniki przyspieszonej hyperfrakcjonacji w leczeniu raka płuca oraz szyjki macicy [24].

Opracowane zostały, Założenia organizacyjno-rozwojowe Rzeszowskiego Ośrodka Onkologicznego", zawierające analizę kadrowo-aparaturową ośrodka oraz określające jego miejsce w regionie [25].

Oddanie do użytku w grudniu 1998 r. zmodernizowanej pracowni bomby kobaltowej Theratron 780 i pracowni fizy- ki medycznej oraz zorganizowana z tej okazji konferencja naukowa były symbolicznym zakończeniem tego ważnego rozdziału rzeszowskiej onkologii.

Prof. Jan Skołyszewski, opiniując „Założenia...” na prośbę Ministerstwa Zdrowia, pisał: „Należy podkreślić, że w ciągu ostatnich kilku lat onkologia rzeszowska dokonała znacznego postępu, związanego głównie z rozwojem fachowej kadry i usprawnieniami organizacyjnymi. Wyrazem tego jest zarówno zwiększenie liczby leczonych chorych, jak i poszerzenie zakresu oraz podniesienie poziomu diagnostyki i terapii nowotworów" [26].

Od listopada 1999 roku Rzeszowski Ośrodek Onkologiczny, uchwałą Sejmiku Województwa Podkarpackiego, został przemianowany na Podkarpackie Centrum Onkologii. Centrum działało w strukturze Wojewódzkiego Szpitala Specjalistycznego w Rzeszowie w ramach nadanego Szpitalowi w tej samej uchwale Statutu [27].

Tym samym kolejną dekadę onkologia rzeszowska rozpoczęła w strukturze przywracającej jej status wojewódzki oraz umożliwiającej dalszy jej rozwój.

Zanim w kolejnej publikacji przedstawione zostaną dalsze lata i wydarzenia, nie sposób nie wspomnieć zasłużonych pracowników PCO, lekarzy, fizyków, techników i pielęgniarek, którzy tworzyli historię onkologii na Podkarpaciu [28].

— dr Józef Małek, w ciągu 45 lat twórca i pierwszy dyrektor rzeszowskiej onkologii, odznaczony Krzyżem Zasługi i Krzyżem Kawalerskim Orderu Odrodzenia Polski,

- dr Julian Wisz, wieloletni kierownik Pracowni Rentgenodiagnostyki,

- Halina Moskwa, przełożona pielęgniarek od początku działania WSO odznaczona Krzyżem Kawalerskim Orderu Odrodzenia Polski,

- dr med. Wiesław Fabisiak, ordynator Oddziału Ginekologii Onkologicznej, zasłużony lekarz i społecznik odznaczony Złotym Krzyżem Zasługi,

- dr Wiesława Rybak, ordynator Oddziału Radioterapii, za swoją działalność zawodową i społeczną odznaczona Srebrnym Krzyżem Zasługi,

- mgr Emilia Samojedny, wieloletnia kierownik Pracowni, a następnie Zakładu Fizyki Medycznej,

- tech. Ludwika Czyż, kierownik Zespołu Techników w Zakładzie Radioterapii, w 1980 roku członek-założyciel pierwszej Komisji Zakładowej NSZZ „Solidarność",

- piel. Małgorzata Materna, wieloletnia pielęgniarka oddziałowa Oddziału Ginekologii Onkologicznej.

\section{Dr n. med. Jan Gawełko}

Instytut Pielęgniarstwa i Nauk o Zdrowiu

Uniwersytet Rzeszowski

e-mail:jangawelko@o2.pl 


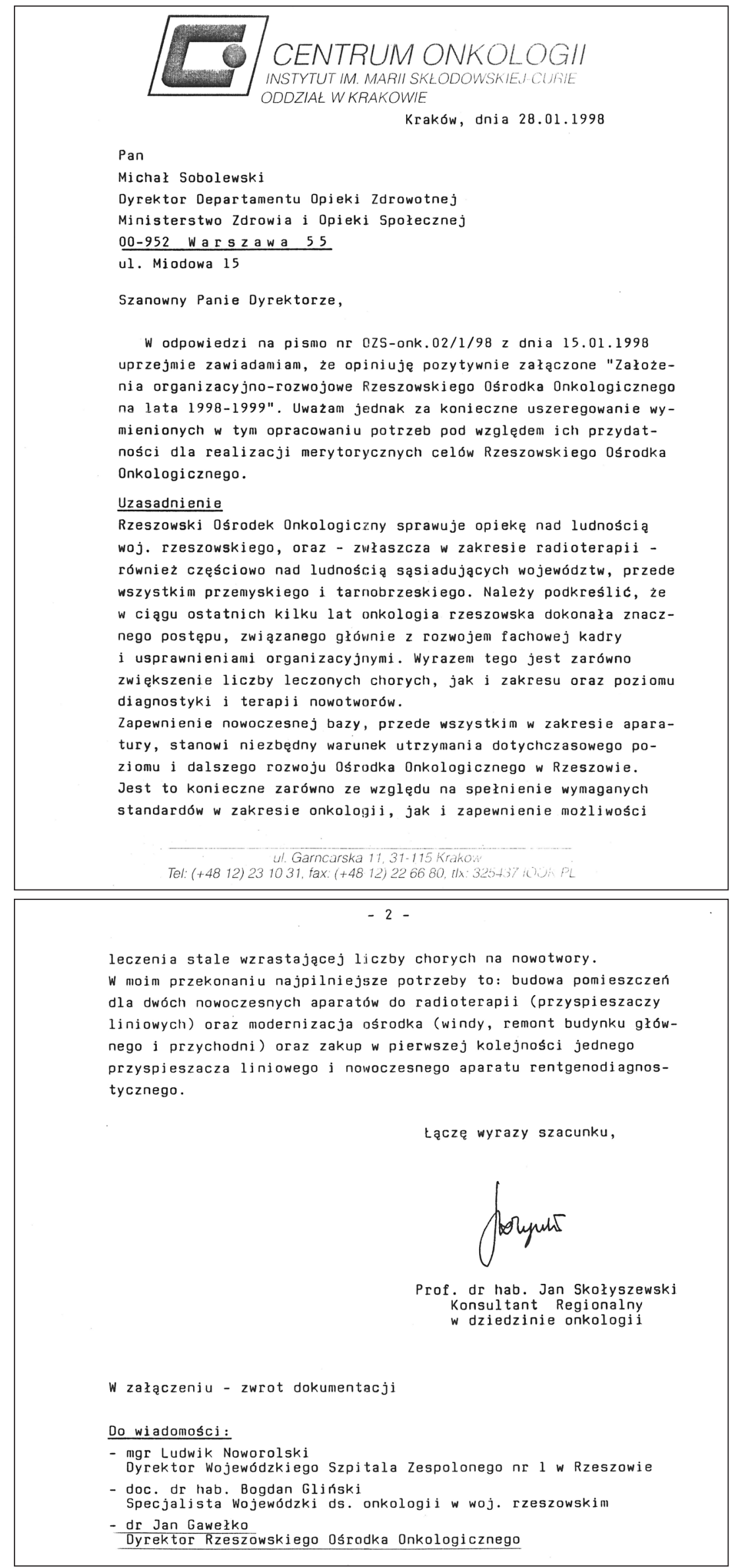

Rycina 3ab. Opinia prof. Jana Skołyszewskiego 


\section{Piśmiennictwo}

1. MałekJ.Problemyonkologicznewwojewództwierzeszowskimmaszynopis. 28.02.1975 r. Oryginał w archiwum PCO.

2. Notatka zastępcy dyrektora ds. ekon.-finansowych. Oryginał w archiwum PCO.

3. Decyzja Ministra Zdr. i Op. Społ. JD-K-2308/88 z dnia 15.04.1988. Odpis w archiwum $P C O$.

4. Pismo ZI-T3/457/410/10/88. Odpis w archiwum PCO.

5. Zarządzenie Nr 75/90 Wojewody Rzeszowskiego z dn. 3 grudnia 1990 r. w sprawie utworzenia Szpitala Wojewódzkiego Nr 2 w Rzeszowie, zmiany nazwy Wojewódzkiego Szpitala Zespolonego w Rzeszowie oraz włączeniu Wojewódzkiego Szpitala Onkologicznego w Rzeszowie do Szpitala Wojewódzkiego Nr 1 w Rzeszowie, AZSW.

6. Gawełko J. Konferencja Naukowa: Onkologia na Podkarpaciu 1952-2011, Rzeszów, 27 września 2011.

7. Zezwolenie CLOR Nr J-6209. Oryginał w archiwum PCO.

8. Zasób archiwalny WSS w Rzeszowie. Akta osobowe nr 10592,10831.

9. Statut oraz postanowienie Sądu Okręgowego w Rzeszowie z dnia 10.10.1990 r. Oryginały w archiwum PCO.

10. Protokoły przyjęcia leków do Apteki Szpitala Wojewódzkiego Nr 1 w Rzeszowie. Oryginały w archiwum PCO.

11. Decyzja SR-432/4/92 z dnia 27.02.1992 r. Oryginał w archiwum PCO.

12. Decyzja SR-432/40/94 z dnia 23.11.1994. Oryginał $w$ archiwum PCO.
13. Zezwolenie Nr D- 8321. Oryginał w archiwum PCO.

14. Decyzja SR 432/11/96 z dnia 22.05.1996. Oryginał w archiwum PCO

15. Zarządzenie nr 32/95 Wojewody rzeszowskiego z dnia 4.04.1995. Archiwum UW w Rzeszowie.

16. Pismo prof. Jana Skołyszewskiego do Min. Zdr. z dnia 28.01.1998. W archiwum PCO.

17. Aneks do zezwolenia nr 1606 Prezesa PAA. Oryginał w archiwum PCO.

18. Decyzja SR-432/38/98 z dnia 2.11.1998. Oryginał w archiwum PCO.

19. Protokół $z$ dnia 9.04.1998. Oryginał $w$ archiwum PCO.

20. Protokół $z$ dnia 16.09.1997. Oryginał $w$ archiwum PCO

21. Protokół zdawczo-odbiorczy 239/98 z dnia 9.12.1998 r. Oryginał w archiwum PCO.

22. Zasób archiwalny WSS w Rzeszowie. Akta osobowe nr 11137,10077, $8167,10095,11144$

23. Gawełko J. Konferencja Naukowa: Onkologia na Podkarpaciu 1952 -2011, Rzeszów, 27 września 2011.

24. Pisma prof. K. Urbańskiego i prof. B. Glińskiego. Oryginały w archiwum PCO.

25. Oryginał $w$ archiwum PCO.

26. Pismo prof. J. Skołyszewskiego do MZ. Oryginał w archiwum PCO.

27. Uchwała nr XII/126?99 Sejmiku Województwa Podkarpackiego z dnia 22.11.1999 $r$

28. Zasób archiwalny WSS w Rzeszowie. Akta osobowe nr 9397, 10077 10021. 10592, 10831. 